\title{
CRESCIMENTO DE BERINJELA VERDE EM DIFERENTES SUBSTRATOS
}

\section{ESTEFÂNIA MARTINS BARDIVIESSO ${ }^{1}$, EDILSON COSTA ${ }^{1}$, MICHELLE NUNES BARCELOS ${ }^{1}$, DIÓGENES MARTINS BARDIVIESSO ${ }^{1}$, LUCAS FRANCISCO MURAKAMI ${ }^{1}$}

1 UEMS/Cassilândia, MS, estefania.bardiviesso@hotmail.com, mestrine@uems.br; michelleuems@gmail.com; bardiviesso@hotmail.com, lucas_f.murakami@hotmail.com;

RESUMO: A berinjela tem como centro de origem a China e a Índia. Seu cultivo apresenta elevada importância pelas propriedades nutricionais dos frutos, principalmente vitaminas e minerais. Este trabalho teve o objetivo de avaliar o crescimento de berinjela verde em diferentes substratos, cultivada em vasos de 13,0 litros. $\mathrm{O}$ experimento foi conduzido num delineamento inteiramente casualizado, com os seguintes tratamentos: $100 \%$ de esterco bovino; $75 \%$ de esterco bovino $+25 \%$ de húmus de minhoca; $50 \%$ de esterco bovino $+50 \%$ de húmus de minhoca; $25 \%$ de esterco bovino $+75 \%$ de húmus de minhoca; e $100 \%$ de húmus de minhoca. A semeadura foi realizada em 08 de dezembro de 2012 e o transplante para os vasos no dia 03 de janeiro de 2013. Foram avaliadas as alturas das plantas e o número de folhas aos 10, 20, 30, 40, 50 e 60 dias após o transplante. Foram determinadas as taxas de crescimento absoluto e relativo. Os substratos compostos por $50 \%$ de esterco bovino $+50 \%$ de húmus de minhoca, $25 \%$ de esterco bovino $+75 \%$ de húmus de minhoca e $100 \%$ de húmus de minhoca são os que proporcionaram o maior desempenho de crescimento. Os substratos com $50 \%$ ou mais de húmus de minhoca podem ser indicados para a produção de berinjela verde em vasos.

PALAVRAS-CHAVE: Solanum melongena, esterco bovino, húmus de minhoca.

\section{EGGPLANT GREEN GROWTH IN DIFFERENT SUBSTRATES}

\begin{abstract}
The eggplant has China and India as its origin center. Its cultivation is important because the fruits have good nutritional properties, mainly for vitamins and minerals. This work aimed to evaluate the green eggplant growth in different substrates, cultivated in pots with 13.0 liters. The experiment was carried out using a randomized design with the following treatments: $100 \%$ of cattle manure; $75 \%$ of cattle manure $+25 \%$ of earthworm compost; $50 \%$ of cattle manure $+50 \%$ of earthworm compost; $25 \%$ of cattle manure $+75 \%$ of earthworm compost; and $100 \%$ of earthworm compost. Seeds were sown in December $8^{\text {th }}, 2012$ and the seedlings were transplanted into the pots in January $3^{\text {rd }}, 2013$. The plants height and the number of leaves were evaluated at 10,20, 30, 40, 50 and 60 days after transplanting (DAT). It was determined the absolute and relative rates of growth. The substrates composed with $50 \%$ of cattle manure $+50 \%$ of earthworm compost, $25 \%$ of cattle manure $+75 \%$ of earthworm compost and $100 \%$ of earthworm compost are those who provided higher growth performance. Substrates with $50 \%$ or more of earthworm compost can be stated for producing green eggplant in pots.
\end{abstract}

KEY-WORDS: Solanum melongena, cattle manure, earthworm compost. 


\section{INTRODUÇÃO}

Pertencente à família das solanáceas, assim como tomate, batata, pimenta, pimentão e jiló, a berinjela (Solanum melongena L.) é uma planta perene, porém considerada planta anual (FILGUEIRA, 2008). Apresenta riqueza nutricional e capacidade de reduzir o colesterol (GONÇALVES et al., 2006), porém suas propriedades medicinais são questionadas por pesquisadores (GUIMARÃES et al., 2000). Possui elevada presença na mesa do consumidor brasileiro (OLIVEIRA et al., 2009). É uma espécie termófila que necessita de alta temperatura para seu desenvolvimento vegetativo e reprodutivo (SOUSA et al., 1997), podendo ser cultivada em várias regiões do Brasil, como por exemplo, a região do Bolsão Sul-MatoGrossense no eixo Cassilândia-Paranaíba, MS.

De acordo com Maggi et al. (2006), nas últimas décadas, houve um crescimento significativo do cultivo protegido de hortaliças. Dentre as hortaliças conduzidas neste sistema de cultivo, pode-se citar a berinjela. $\mathrm{O}$ aumento do interesse pelo cultivo protegido de berinjela pode ser explicado por Bezerra (2003), que relata que esse sistema de cultivo permite a produção em qualquer época do ano, precocidade na colheita e melhor controle fitossanitário. Além disso, Costa et al. (2012a) relatam que a tecnologia do cultivo protegido resulta em avanços nas melhores condições de desenvolvimento da muda, tanto nos aspectos fitotécnicos como fitossanitários.

Ultimamente o interesse pelo cultivo de hortaliças, dentre elas, a berinjela em recipientes com substrato tem aumentado. Essa ideia tem sido adotada de forma crescente, principalmente pelo fato de possibilitar a redução de problemas que normalmente são encontrados em solos de cultivo protegido, como a salinização e a infestação de patógenos. Além dos benefícios citados anteriormente, Melo et al. (2012) cita que com o cultivo de hortaliças em recipientes com substratos, têm sido observados incrementos na produtividade e qualidade de frutos.

O uso de substratos, especialmente alternativos, de baixo custo e com disponibilidade no local de produção, tem proporcionado qualidade superior às plantas e propiciado incremento á produção. Segundo Schmitz et al. (2002) o substrato agrícola deve possuir características desejáveis como baixo custo, fácil aquisição, nutrientes suficientes para o desenvolvimento vegetal, capacidade de troca catiônica, esterilidade biológica, porosidade, retenção de umidade e uniformidade. Requisitos estes para propiciar às plantas as melhores condições para seu desenvolvimento e incremento na produtividade.

O substrato possui a função especial de fixar o sistema radicular da planta num recipiente (MELO et al., 2007). No mercado, existem várias marcas, porém, num sistema produtivo, buscam-se alternativas para diminuir os custos de produção (COSTA et al., 2012b), como por exemplo o uso de estercos (bovino, suíno, aves, etc.) e/ou húmus de minhoca. A utilização de substratos alternativos para a produção vegetal contribui para o aproveitamento de resíduos e para a sustentabilidade na agricultura brasileira.

O Estado de Mato Grosso do Sul importa elevada quantidade de produtos hortícolas de outros estados brasileiros, especialmente São Paulo e Paraná, chegando a patamares de 85\% dos produtos consumidos no Estado (BOLETIM ANUAL, 2014). Estes índices indicam a necessidades de pesquisas em toda cadeia produtiva de hortaliças que poderiam incrementar a atividade na região do Bolsão Sul-Mato-Grossense, onde se encontram pequenos produtores, que circundam os centros urbanos e abastecem os mercados locais. Baseado nestas informações e na necessidade de ampliar a oferta de hortaliças de qualidade no Estado de 
Mato Grosso do Sul, este trabalho teve como objetivo avaliar a o crescimento da berinjela verde em substratos alternativos no cultivo em vasos sob ambiente protegido.

\section{MATERIAL E MÉTODOS}

O experimento foi realizado em área experimental da Universidade Estadual de Mato Grosso do Sul (UEMS), na Unidade Universitária de Cassilândia, no período de dezembro de 2012 a janeiro de 2013. A região se localiza em altitude de $516 \mathrm{~m}$, longitude de $-51^{\circ} 44^{\prime} 03^{\prime \prime}$ e latitude de $-19^{\circ}$ 06'48" (Estação automática CASSILANDIA-A742). O clima da região, de acordo com a classificação de Köppen, é tropical com estação seca.

O experimento foi conduzido num delineamento inteiramente casualizado, com 5 tratamentos e 10 repetições, onde cada repetição foi o vaso. Foram testados os seguintes tratamentos: T1: $100 \%$ de esterco bovino $+0 \%$ de húmus de minhoca; T2: $75 \%$ de esterco bovino $+25 \%$ de húmus de minhoca; T3: $50 \%$ de esterco bovino $+50 \%$ de húmus de minhoca; T4: $25 \%$ de esterco bovino $+75 \%$ de húmus de minhoca e T5: $0 \%$ de esterco bovino $+100 \%$ de húmus de minhoca.

As sementes de berinjela verde foram obtidas pela seleção de frutos de um produtor local. As mudas foram produzidas em bandeja de polietileno de 72 células, semeadas no dia 8/12/2012. O transplante para os vasos plásticos de 13 litros ocorreu no dia 03/01/2013. Foi utilizado um ambiente protegido chamado de telado agrícola $(8,00 \mathrm{~m} \times 18,00 \mathrm{~m} \mathrm{x} \mathrm{3,50} \mathrm{m),} \mathrm{de}$ estrutura em aço galvanizado, coberto de tela termorrefletora de $50 \%$ de sombreamento e lateral com tela preta de monofilamento, malha para 50\% de sombra, com fechamento em $90^{\circ}$.

Foram mensuradas a altura de plantas (AP) e o número de folhas (NF) aos 10, 20, 30, 40, 50 e 60 dias após o transplante (DAT). A altura da planta $(\mathrm{cm})$ foi mensurada com o auxílio de trena.

A partir dos valores médios decenais de altura de planta foram calculadas suas respectivas taxas de crescimento absoluto (TCA) e taxas de crescimento relativo (TCR) das alturas de plantas conforme as Equações. 1 e 2 (BENINCASA, 2003).

Eq. 1

Eq. 2

em que: TCA - taxa de crescimento absoluto, TCR - taxa de crescimento relativo, ln logaritmo natural, V1- crescimento da planta no tempo t1, V2- crescimento da planta no tempo t2.

A taxa de crescimento absoluto (TCA) e a taxa de crescimento relativo (TCR) da altura de planta foram avaliadas em cinco períodos $(10$ - 20, 20 - 30, 30 - 40, 40 - 50 e 50 - 60 DAT).

No esterco bovino foi realizado o processo de compostagem por trinta dias. Após secado, foi homogeneizado e, posteriormente, peneirado. O húmus de minhoca foi adquirido de uma empresa frigorífica, localizada em Dois Irmãos do Buriti - MS. As minhocas eram alimentadas com resíduo orgânico do frigorífico que continham restos de vísceras, sangue, 
gorduras, rumem entre outros. As características do esterco bovino e do húmus de minhoca são apresentadas na Tabela 1.

Os dados foram submetidos à análise de variância em cada período de avaliação e as médias comparadas pelo teste de Tukey a 5\% de probabilidade, com o uso do software Sisvar (FERREIRA, 2010).

Tabela 1. Análise química do esterco bovino (E) e do húmus de minhoca $(\mathrm{H})$ utilizado no experimento. Cassilândia-MS, 2013.

\begin{tabular}{|c|c|c|c|c|c|c|c|c|}
\hline & \multicolumn{8}{|c|}{------------------------------------------ $\mathrm{g} \mathrm{kg}^{-1}$----------------------------------------- } \\
\hline * & $\mathrm{N}$ & $\mathrm{P}$ & $\mathrm{K}$ & $\mathrm{Ca}$ & $\mathrm{Mg}$ & $\mathrm{S}$ & $\mathrm{C}$ & MO \\
\hline $\mathrm{H}$ & 14,80 & 4,46 & 1,00 & 26,70 & 12,50 & 3,53 & 163,00 & 281,00 \\
\hline $\mathrm{E}$ & 18,4 & 1,71 & 1,00 & 15,05 & 0,70 & 1,95 & 141,00 & 244,00 \\
\hline & & & & & -------- & $--\mathrm{mg} \mathrm{kg}^{-1}$ & & \\
\hline & $\mathrm{pH}$ & $\mathrm{U}$ & $\mathrm{C} / \mathrm{N}$ & $\mathrm{Cu}$ & $\mathrm{Zn}$ & $\mathrm{Fe}$ & $\mathrm{Mn}$ & B \\
\hline $\mathrm{H}$ & 6,90 & 13,46 & 11,01 & 30,00 & 130,00 & 14800,00 & 370,00 & 14,40 \\
\hline $\mathrm{E}$ & 4,90 & 38,91 & 7,66 & 18,50 & 125,00 & 6830,00 & 214,00 & 14,00 \\
\hline
\end{tabular}

\section{RESULTADOS E DISCUSSÃO}

Foi verificado que até 40 dias após o transplante (DAT) não houve diferença significativa nos tratamentos para o número de folhas. Aos 50 e 60 DAT as plantas cultivadas nos substratos contendo $50 \%$ ou mais húmus de minhoca apresentaram maior número de folhas (Tabela 2). Aos 60 DAT as plantas apresentavam, em média, 30,8 folhas por planta, resultado inferior ao observado por Maldaner et al. (2009), no final do cultivo aos 107 DAT, que verificaram 51,5 folhas por planta em cultivo com uma haste e 31,5 folhas por planta no cultivo com duas hastes, em cultivo no solo sob estufa plástica. Aos 25 DAT, Oliveira et al. (2012) observaram 7,6 folhas por planta no crescimento inicial da berinjela utilizando fitomassa de Tefhrosia cândida cobrindo o solo, com e sem $\mathrm{N}$ mineral, em plantio direto sobre um Latossolo Amarelo muito argiloso, em Manaus-AM, resultado este inferior ao obtido no presente trabalho aos 20 DAT.

Tabela 2. Número médio de folhas por planta da berinjela verde. Cassilândia-MS, 2012-2013.

\begin{tabular}{lllllll}
\hline \multicolumn{1}{c}{ Tratamentos } & $10 \mathrm{DAT}$ & $20 \mathrm{DAT}$ & $30 \mathrm{DAT}$ & $40 \mathrm{DAT}$ & $50 \mathrm{DAT}$ & $60 \mathrm{DAT}$ \\
\hline $100 \% \mathrm{E}+0 \% \mathrm{H}$ & $4,9 \mathrm{a}$ & $8,0 \mathrm{a}$ & $10,5 \mathrm{a}$ & $13,8 \mathrm{a}$ & $20,8 \mathrm{bc}$ & $20,9 \mathrm{~b}$ \\
$75 \% \mathrm{E}+25 \% \mathrm{H}$ & $4,4 \mathrm{a}$ & $7,4 \mathrm{a}$ & $8,9 \mathrm{a}$ & $12,9 \mathrm{a}$ & $19,5 \mathrm{c}$ & $23,3 \mathrm{~b}$ \\
$50 \% \mathrm{E}+50 \% \mathrm{H}$ & $4,9 \mathrm{a}$ & $8,0 \mathrm{a}$ & $11,2 \mathrm{a}$ & $15,2 \mathrm{a}$ & $29,3 \mathrm{ab}$ & $35,7 \mathrm{a}$ \\
$25 \% \mathrm{E}+75 \% \mathrm{H}$ & $4,6 \mathrm{a}$ & $8,0 \mathrm{a}$ & $11,0 \mathrm{a}$ & $14,0 \mathrm{a}$ & $26,3 \mathrm{abc}$ & $39,4 \mathrm{a}$ \\
$0 \% \mathrm{E}+100 \% \mathrm{H}$ & $4,9 \mathrm{a}$ & $8,0 \mathrm{a}$ & $10,6 \mathrm{a}$ & $16,1 \mathrm{a}$ & $30,6 \mathrm{a}$ & $34,9 \mathrm{a}$ \\
\hline $\mathrm{CV}(\%)$ & 10,7 & 9,3 & 18,5 & 36,8 & 2,94 & $19,3 \mathrm{a}$ \\
Teste F & $2,0^{\mathrm{NS}}$ & $1,33^{\mathrm{NS}}$ & $2,2^{\mathrm{NS}}$ & $0,6^{\mathrm{NS}}$ & $4,5^{0,01}$ & $18,9^{0,01}$ \\
\hline
\end{tabular}

* Médias seguidas de mesma letra minúscula na coluna não diferem pelo teste de Tukey a 5\% de probabilidade para cada avaliação; ** $\mathrm{E}=$ esterco bovino; $\mathrm{H}=$ húmus de minhoca; $\mathrm{CV}=$ coeficiente de variação (\%); Fcal = F calculado; ${ }^{\mathrm{NS}}=$ não significativo pelo teste $\mathrm{F} ;{ }^{0,05}=$ significativo a $5 \%$ de probabilidade pelo teste $\mathrm{F} ;{ }^{0,01}=$ significativo a $1 \%$ de probabilidade pelo teste F. 
Foram encontrados alguns coeficientes de variação altos nas avaliações, como o constatado no número médio de folhas aos 40 DAT (Tabela 2), que foi de 36,8\%. Apesar de o experimento ter sido conduzido em cultivo protegido, o qual reduz as variações ambientais, o mesmo não reduz a variação do fator genético. Na maioria dos experimentos desenvolvidos neste sistema, são utilizados híbridos, os quais apresentam mínima variabilidade genética. Neste experimento, foi utilizado um material genético "exótico", obtido através da seleção de um produtor de hortaliças convencional, portanto, a variabilidade genética pode ser alta, sendo esta a possível explicação de os valores de coeficiente de variação serem superiores aos observados normalmente em experimentos conduzidos em ambiente protegido.

No cultivo em vasos de 22,5 litros, sob ambiente protegido, Silva et al. (2013) avaliando níveis de salinidade e manejo da fertirrigação sobre características da berinjela, verificaram média de 169 folhas por planta aos 140 dias , muito superior ao observado no presente trabalho aos 60 DAT (30,8 folhas por planta). Carvalho et al. (2004) observaram média de 25,8 folhas por planta aos 40 DAT e 57,2 folhas por planta aos 60 DAT, superiores aos observados no presente estudo.

Observa-se que houve maior influencia da elevada porcentagem húmus de minhoca do que da maior porcentagem do esterco bovino no desenvolvimento da planta, e segundo Streck et al. (2003) o número de folhas acumuladas, resultado da taxa de surgimento de folhas com o tempo, é uma variável importante para determinação do desenvolvimento vegetal. Sinclair et al. (2004) relatam que o número de folhas está diretamente relacionado com o aparecimento de alguns órgãos na planta e com a expansão da área foliar, responsável pela interceptação da radiação fotossinteticamente ativa.

Aos 10 DAT não se observou diferença na altura de plantas nos diferentes substratos testados. Aos 20 DAT as plantas dos substratos $50 \% \mathrm{E}+50 \% \mathrm{H}$ e $0 \% \mathrm{E}+100 \% \mathrm{H}$ estavam maiores que as cultivadas no substrato $75 \% \mathrm{E}+25 \% \mathrm{H}$. De 30 a 50 DAT as plantas cultivadas no substrato $75 \% \mathrm{E}+25 \% \mathrm{H}$ estavam menores que as cultivadas nos demais substratos. Aos 60 DAT as plantas dos substratos com 50 e $75 \%$ de húmus de minhoca estavam maiores que as cultivadas nos substratos com 0 e $25 \%$. De maneira geral, as menores plantas foram verificadas no substrato com $75 \%$ de esterco bovino $+25 \%$ de húmus de minhoca, onde ao longo de todo o experimento constatou-se o crescimento irregular dessas plantas (Tabela 3). Em média, foi observada altura de $27,9 \mathrm{~cm}$ aos 20 DAT, resultado este superior ao obtido aos 25 DAT por Oliveira et al. (2012) que observaram altura de $16,3 \mathrm{~cm}$ no crescimento inicial da berinjela em plantio direto. Aos 121 DAT, Queiroz et al. (2013) avaliando a tolerância da berinjela à salinidade, cultivada em substrato de fibra de coco, obtiveram plantas com 79,12 $\mathrm{cm}$ de altura, sendo inferior ao obtido no presente trabalho aos 60 DAT $(111,98 \mathrm{~cm})$.

Tabela 3. Altura de planta de berinjela verde. Cassilândia-MS, 2012-2013.

\begin{tabular}{lllllll}
\hline \multicolumn{1}{c}{ Tratamentos } & $10 \mathrm{DAT}$ & $20 \mathrm{DAT}$ & $30 \mathrm{DAT}$ & $40 \mathrm{DAT}$ & $50 \mathrm{DAT}$ & $60 \mathrm{DAT}$ \\
\hline $100 \% \mathrm{E}+0 \% \mathrm{H}$ & $10,4 \mathrm{a}$ & $28,2 \mathrm{ab}$ & $40,9 \mathrm{a}$ & $64,3 \mathrm{a}$ & $85,5 \mathrm{~b}$ & $100,9 \mathrm{~b}$ \\
$75 \% \mathrm{E}+25 \% \mathrm{H}$ & $10,5 \mathrm{a}$ & $22,6 \mathrm{~b}$ & $29,0 \mathrm{~b}$ & $46,3 \mathrm{~b}$ & $65,2 \mathrm{c}$ & $97,9 \mathrm{~b}$ \\
$50 \% \mathrm{E}+50 \% \mathrm{H}$ & $12,0 \mathrm{a}$ & $29,7 \mathrm{a}$ & $44,4 \mathrm{a}$ & $73,6 \mathrm{a}$ & $94,8 \mathrm{ab}$ & $123,9 \mathrm{a}$ \\
$25 \% \mathrm{E}+75 \% \mathrm{H}$ & $10,5 \mathrm{a}$ & $29,1 \mathrm{ab}$ & $41,8 \mathrm{a}$ & $71,7 \mathrm{a}$ & $102,9 \mathrm{a}$ & $122,2 \mathrm{a}$ \\
$0 \% \mathrm{E}+100 \% \mathrm{H}$ & $11,5 \mathrm{a}$ & $30,0 \mathrm{a}$ & $43,0 \mathrm{a}$ & $67,5 \mathrm{a}$ & $94,2 \mathrm{ab}$ & $115,0 \mathrm{ab}$ \\
\hline $\mathrm{CV}(\%)$ & 15,2 & 19,0 & 18,9 & 19,5 & 15,0 & 12,7 \\
Fcal & $2,0^{\mathrm{NS}}$ & $3,3^{0,05}$ & $6,7^{0,01}$ & $7,4^{0,01}$ & $11,7^{0,01}$ & $7,2^{0,01}$ \\
\hline
\end{tabular}

* Médias seguidas de mesma letra minúscula na coluna não diferem pelo teste de Tukey a 5\% de probabilidade para cada variável; ** $\mathrm{E}=$ esterco bovino; $\mathrm{H}=$ húmus de minhoca; $\mathrm{CV}=$ coeficiente de variação $(\%) ; \mathrm{Fcal}=\mathrm{F}$ calculado; ${ }^{\mathrm{NS}}=$ não 
significativo pelo teste $\mathrm{F} ;{ }^{0,05}=$ significativo a $5 \%$ de probabilidade pelo teste $\mathrm{F} ;{ }^{0,01}=$ significativo a $1 \%$ de probabilidade pelo teste F.

No estudo de níveis de déficit hídrico em diferentes estádios fenológicos da cultura da berinjela, Carvalho et al. (2004) verificaram plantas com altura média 54,33 cm aos 40 DAT, $77,0 \mathrm{~cm}$ aos 60 DAT e 100,66 cm aos 100 DAT utilizando reposição de $100 \%$ da água no solo. Verifica-se que estes resultados são inferiores ao observado no presente trabalho, onde foram obtidas alturas médias de $64,7 \mathrm{~cm}$ aos 40 DAT e 112,0 $\mathrm{cm}$ aos 60 DAT.

No presente estudo a taxa de crescimento absoluto da altura foi em média de $2,02 \mathrm{~cm}$ dia $^{-1}$ (Tabela 4). Maia Junior et al (2013) estudando a taxas de crescimento de cultivares de girassol sob diferentes regimes hídricos verificaram taxa de crescimento absoluto da altura de $1,52 \mathrm{~cm} \mathrm{dia}^{-1}$. No estudo de comportamento morfofsiológico da mamoneira BRS Energia submetida à irrigação com água salina, Santos et al. (2013) observaram máxima taxa de crescimento absoluto da altura de $2,77 \mathrm{~cm} \mathrm{dia}^{-1}$.

Tabela 4. Taxa de crescimento absoluto da altura de planta da berinjela verde. CassilândiaMS, 2012-2013.

\begin{tabular}{llllll}
\hline \multicolumn{1}{c}{ Tratamentos } & $10-20$ DAT & $20-30$ DAT & $30-40$ DAT & $40-50$ DAT & $50-60$ DAT \\
\hline $100 \% \mathrm{E}+0 \% \mathrm{H}$ & $1,78 \mathrm{ab}$ & $1,28 \mathrm{ab}$ & $2,34 \mathrm{ab}$ & $2,12 \mathrm{bc}$ & $1,54 \mathrm{~b}$ \\
$75 \% \mathrm{E}+25 \% \mathrm{H}$ & $1,21 \mathrm{~b}$ & $0,65 \mathrm{~b}$ & $1,73 \mathrm{~b}$ & $1,89 \mathrm{c}$ & $3,27 \mathrm{a}$ \\
$50 \% \mathrm{E}+50 \% \mathrm{H}$ & $1,77 \mathrm{ab}$ & $1,47 \mathrm{a}$ & $2,92 \mathrm{a}$ & $2,12 \mathrm{bc}$ & $2,91 \mathrm{a}$ \\
$25 \% \mathrm{E}+75 \% \mathrm{H}$ & $1,87 \mathrm{a}$ & $1,27 \mathrm{ab}$ & $2,99 \mathrm{a}$ & $3,12 \mathrm{a}$ & $1,93 \mathrm{~b}$ \\
$0 \% \mathrm{E}+100 \% \mathrm{H}$ & $1,85 \mathrm{a}$ & $1,31 \mathrm{a}$ & $2,45 \mathrm{ab}$ & $2,67 \mathrm{ab}$ & $2,08 \mathrm{~b}$ \\
\hline $\mathrm{CV}(\%)$ & 26,9 & 43,0 & 31,4 & 22,7 & 25,1 \\
Fcal & $3,7^{0,05}$ & $3,8^{0,01}$ & $4,3^{0,01}$ & $8,6^{0,01}$ & $14,9^{0,01}$ \\
\hline
\end{tabular}

* Médias seguidas de mesma letra minúscula na coluna não diferem pelo teste de Tukey a 5\% de probabilidade para cada variável; ** $\mathrm{E}=$ esterco bovino; $\mathrm{H}=$ húmus de minhoca; $\mathrm{CV}=$ coeficiente de variação $(\%) ; \mathrm{Fcal}=\mathrm{F}$ calculado; ${ }^{\mathrm{NS}}=$ não significativo pelo teste $\mathrm{F} ;{ }^{0,05}=$ significativo a $5 \%$ de probabilidade pelo teste $\mathrm{F} ;{ }^{0,01}=$ significativo a $1 \%$ de probabilidade pelo teste F.

A taxa de crescimento relativo das plantas cultivadas no substrato $75 \% \mathrm{E}+25 \% \mathrm{H}$ no final do experimento (50-60DAT) foram maiores que as taxas dos demais substratos, evidenciando o crescimento irregular das plantas nesses substratos, desde 10 até 50 DAT (Tabela 5).

Observa-se que taxa de crescimento relativo da altura de planta (TCR) foi em média de $0,046 \mathrm{~cm} \mathrm{~cm}^{-1} \mathrm{dia}^{-1}$ (Tabela 5). A média da TCR constatada neste trabalho foi superior a encontrada por Cardoso et al. (2008), que estudando o crescimento de berinjela em função de doses de esterco bovino e de termofosfato magnesiano, constataram o valor máximo de 0,029 $\mathrm{cm} \mathrm{cm}^{-1} \mathrm{dia}^{-1}$.

Maia Junior et al (2013) estudando a taxas de crescimento de cultivares de girassol sob diferentes regimes hídricos verificaram taxa de crescimento relativo da altura de $0,033 \mathrm{~cm} \mathrm{~cm}^{-}$ ${ }^{1} \mathrm{dia}^{-1}$. No estudo de comportamento morfofisiológico da mamoneira BRS Energia submetida à irrigação com água salina, Santos et al. (2013) observaram taxa de crescimento relativo da altura de $0,047 \mathrm{~cm} \mathrm{~cm}^{-1} \mathrm{dia}^{-1}$. 
Tabela 5. Taxa de crescimento relativo da altura de planta de berinjela verde. Cassilândia-MS, 2012-2013.

\begin{tabular}{llllll}
\hline \multicolumn{1}{c}{ Tratamentos } & $10-20 \mathrm{DAT}$ & $20-30 \mathrm{DAT}$ & $30-40 \mathrm{DAT}$ & $40-50 \mathrm{DAT}$ & $50-60 \mathrm{DAT}$ \\
\hline $100 \% \mathrm{E}+0 \% \mathrm{H}$ & $0,098 \mathrm{a}$ & $0,037 \mathrm{a}$ & $0,047 \mathrm{a}$ & $0,029 \mathrm{ab}$ & $0,017 \mathrm{~b}$ \\
$75 \% \mathrm{E}+25 \% \mathrm{H}$ & $0,071 \mathrm{~b}$ & $0,025 \mathrm{a}$ & $0,041 \mathrm{a}$ & $0,038 \mathrm{a}$ & $0,045 \mathrm{a}$ \\
$50 \% \mathrm{E}+50 \% \mathrm{H}$ & $0,091 \mathrm{ab}$ & $0,041 \mathrm{a}$ & $0,051 \mathrm{a}$ & $0,025 \mathrm{~b}$ & $0,027 \mathrm{~b}$ \\
$25 \% \mathrm{E}+75 \% \mathrm{H}$ & $0,103 \mathrm{a}$ & $0,036 \mathrm{a}$ & $0,054 \mathrm{a}$ & $0,036 \mathrm{ab}$ & $0,017 \mathrm{~b}$ \\
$0 \% \mathrm{E}+100 \% \mathrm{H}$ & $0,096 \mathrm{a}$ & $0,036 \mathrm{a}$ & $0,044 \mathrm{a}$ & $0,034 \mathrm{ab}$ & $0,020 \mathrm{~b}$ \\
\hline $\mathrm{CV}(\%)$ & 19,4 & 38,0 & 26,9 & 30,0 & 36,9 \\
Fcal & $4,8^{0,01}$ & $1,9^{\mathrm{NS}}$ & $1,8^{\mathrm{NS}}$ & $2,8^{0,05}$ & $16,7^{0,01}$ \\
\hline
\end{tabular}

* Médias seguidas de mesma letra minúscula na coluna não diferem pelo teste de Tukey a 5\% de probabilidade para cada variável; ** $\mathrm{E}=$ esterco bovino; $\mathrm{H}=$ húmus de minhoca; $\mathrm{CV}=$ coeficiente de variação (\%); Fcal $=\mathrm{F}$ calculado; ${ }^{\mathrm{NS}}=$ não significativo pelo teste $\mathrm{F} ;{ }^{0,05}=$ significativo a $5 \%$ de probabilidade pelo teste $\mathrm{F} ;{ }^{0,01}=$ significativo a $1 \%$ de probabilidade pelo teste F.

\section{CONCLUSÕES}

Os substratos compostos por $50 \%$ de esterco bovino $+50 \%$ de húmus de minhoca, $25 \%$ de esterco bovino $+75 \%$ de húmus de minhoca e $100 \%$ de húmus de minhoca são os que proporcionaram o maior desempenho de crescimento.

Os substratos com $50 \%$ ou mais de húmus de minhoca podem ser indicados para a produção de berinjela verde em vasos.

\section{AGRADECIMENTOS}

À Fundação de Apoio ao Desenvolvimento do Ensino, Ciência e Tecnologia do Estado de Mato Grosso do Sul (FUNDECT), Proc. No 23/200.647/2012. À Universidade Estadual de Mato Grosso do Sul (UEMS), Unidade Universitária de Cassilândia (UUC). Ao Conselho Nacional de Desenvolvimento Científico e Tecnológico (CNPq), Proc. No 300829/2012-4.

\section{REFERÊNCIAS BIBLIOGRÁFICAS}

BENINCASA, M. M. P. Análise de crescimento de plantas. Jaboticabal-SP: FUNEP, 2003. $41 \mathrm{p}$.

BEZERRA, F. C. Produção de mudas de hortaliças em ambiente protegido. Fortaleza-CE: Embrapa agroindústria tropical, 2003. 19 p. (Documento 72)

BOLETIM ANUAL 2014. Comercialização anual da CEASA/MS em 2013. Campo Grande-MS: Governo do Estado, 2014. Disponível em: www.ceasa.ms.gov.br. Acesso em: 01 mai. 2014.

CARDOSO, M. O.; PEREIRA, W. E.; OLIVEIRA, A. P.; SOUZA, A. P. Eggplant growth as affected by bovine manure and magnesium thermophosphate rates. Scientia Agrícola, Piracicaba-SP, v. 65, n. 1, p. 77-86, 2008. 
CARVALHO, J. A.; SANTANA, M. J.; PEREIRA, G. M.; PEREIRA, J. R. D. QUEIROZ, T. M. níveis de déficit hídrico em diferentes estádios fenológicos da cultura da berinjela (Solanum melongena L.). Engenharia Agrícola, Jaboticabal-SP, v. 24, n. 2, p. 320-327, 2004.

COSTA, E.; VIEIRA, L. C. R.; LEAL, P. A. M.; JARA, M. C. S.; SILVA, P. N. L. Substrate with Organosuper ${ }^{\circledR}$ for cucumber seedlings formation in protected environments and polystyrene trays. Engenharia Agrícola, Jaboticabal-SP, v. 32, n. 2, p. 226-235, 2012 a.

COSTA, E.; PEGORARE, A. B.; LEAL, P. A. M.; ESPINDOLA, J. S.; SALAMENE, L. C. P. Formação de mudas e produção de frutos de berinjela. Científica, Jaboticabal-SP, v. 40, n. 1, p. 12-20, 2012b.

FERREIRA, D. F. SISVAR - Sistema de análise de variância. Versão 5.3. Lavras-MG: UFLA, 2010.

FILGUEIRA, F. A. R. Novo manual de olericultura: agrotecnologia moderna na produção e comercialização de hortaliças. 3. ed. Viçosa-MG: UFV, 2008. 421p.

GONÇALVES, M. C. R.; DINIZ, M. F. F. M; BORBA, J. D. C.; NUNES, X. P.; BARBOSA FILHO, J. M. Berinjela (Solanummelogena L.) - mito ou realidade no combate as dislipidemias. Revista Brasileira de Farmacognosia, Curitiba-PR, v. 16, n. 2, p. 252-257, 2006.

GUIMARAES, P. R.; GALVÃO, A. M. P.; BATISTA, C. M.; AZEVEDO, G. S.; OLIVEIRA, R. D.; LAMOUNIER, R. P.; FREIRE, N.; BARROS, A. M. D.; SAKURAI, E.; OLIVEIRA, J. P.; VIEIRA, E. C.; ALVAREZ-LEITE, J. I. Eggplant (Solanum melongena) infusion has a modest and transitory effect on hypercholesterolemic subjects. Brazilian Journal of Medical and Biological Research, Ribeirão Preto-SP, v. 33, n. 9, p. 1027-1036, 2000.

MAGGI, M. F.; KLAR, A. E.; JADOSKI, C. J.; ANDRADE, A. R. S. Produção de variedades de alface sob diferentes potenciais de água no solo em ambiente protegido. Irriga, BotucatuSP, v. 11, n. 3, p. 415-427, 2006.

MAIA JUNIOR, S. O.; ANDRADE, J. R.; ARAÚJO, D. L.; SOUSA, J. S.; MEDEIROS, I. F. S. Taxas de crescimento de cultivares de girassol sob diferentes regimes hídricos. Revista Verde, Mossoró-RN, v. 8, n. 3, p. 150-155, 2013.

MALDANER, I. C.; GUSE, F. I.; STRECK, N. A. HELDWEIN, A. B.; LUCAS, D. D. P.; LOOSE, L. H. Filocrono, área foliar e produtividade de frutos de berinjela conduzidas com uma e duas hastes por planta em estufa plástica. Ciência Rural, Santa Maria-RS, v. 39, n. 3, p. 671-677, 2009.

MElO, D, M.; CASTOLDI, R.; CHARLO, H. C. O.; GALATTI, F. S.; BRAZ, L. T. Produção e qualidade de melão rendilhado sob diferentes substratos em cultivo protegido. Revista Caatinga, Mossoró-RN, v. 25, n. 1, p. 58-66, 2012.

MELO, A. S.; COSTA, C. X.; BRITO, M. E. B.; VIEGAS, P. R. A.; SILVA JÚNIOR, C. D. Produção de mudas de mamoeiro em diferentes substratos e doses de fósforo. Revista Brasileira Ciência Agrária, Recife-PE, v. 2, n. 4, p. 257-261, 2007.

OLIVEIRA, M. L.; CARDOSO, M. O.; KANO, C. Crescimento inicial na berinjela em plantio direto com fitomassa da leguminosa arbustiva Tefhrosia cândida cobrindo o solo, com e sem nitrogênio mineral. Horticultura Brasileira, Brasília-DF, v. 30 (suplemento), p. S3190-S3195, 2012. 
OLIVEIRA, A. B.; HERNANDEZ, F. F. F. ; ASSIS JÚNIOR, R. N. Absorção de nutrientes em mudas de berinjela cultivadas em pó de coco verde. Caatinga, Mossoró-RN, v. 22, n. 2, p. 139-143, 2009.

QUEIROZ, I. S. R.; LEITÃO, A. R. F.; FERREIRA, L. L.; DIAS, N. S.; COSME, C. R.; MOTA, A. F. Tolerância da berinjela à salinidade cultivada em substrato de fibra de coco. Agropecuária Científica no Semi-Árido, Campina Grande-RN, v. 9, n. 2, p. 15-20, 2013.

SANTOS, J. B.; SANTOS, D. B.; AZEVEDO, C. V. REBEQUI, A. M.; CAVALCANTE, L. F.; CAVALCANTE, I. H. L. Comportamento morfofsiológico da mamoneira BRS Energia submetida à irrigação com água salina. Revista Brasileira de Engenharia Agrícola e Ambiental, Campina Grande-RN, v. 17, n. 2, p. 145-152, 2013.

SCHMITZ, J. A. K; SOUZA, P. V. D. de; KAMPF, A. N. Propriedades químicas e físicas de substratos de origem mineral e orgânica para o cultivo de mudas em recipientes. Ciência Rural, Santa Maria-RS, v. 32, n. 6, p. 937-944, 2002.

SILVA, E. M.; LIMA, C. J. G. S.; DUARTE, S. N.; BARBOSA, F. S.; RAFAEL MASCHIO, R. Níveis de salinidade e manejo da fertirrigação sobre características da berinjela cultivada em ambiente protegido. Revista Ciência Agronômica, Fortaleza-CE, v. 44, n. 1, p. 150-158, 2013.

SINCLAIR, T. R.; GILBERT, R. A.; PERDOMO, R. E.; SHINE JUNIOR, J. M.; POWELL, G.; MONTES, G. Sugarcane leaf area development under field conditions in Florida ,USA. Field Crops Research, v. 88, p. 171-178, 2004.

SOUSA, J.A. LEDO, F.J.S.; SILVA, M.R. Produção de mudas de hortaliças em recipientes. Rio Branco-AC: Embrapa-CPAF/AC, 1997. 19 p. (Embrapa-CPAF/AC. Circular Técnica, 19).

STRECK, N.A.; WEISS, A.; XUE, Q.; BAENZIGER, P.S. Incorporating a chronology response function into the prediction of leaf appearance rate in winter wheat. Annals of Botany, v. 92, p. 181-190, 2003. 